\title{
Out of the Desert: The 4th TEMTIA Meeting on New Advances in Development, Fibrosis and Cancer
}

\author{
Erik W. Thompson ${ }^{\mathrm{a}}$ Raymond Runyan ${ }^{c}$ Pierre Savagner ${ }^{\mathrm{d}}$ Donald F. Newgreen ${ }^{\mathrm{b}}$ \\ ${ }^{a}$ Invasion and Metastasis Unit, St. Vincent's Institute and University of Melbourne, Department of Surgery, \\ St. Vincent's Hospital, Melbourne, Vic., and b Embryology Laboratory, Murdoch Children's Research Institute, \\ Royal Children's Hospital, Parkville, Vic., Australia; 'Department of Cell Biology and Anatomy, University of Arizona, \\ Tucson, Ariz., USA; ${ }^{d}$ Génotypes et Phénotypes Tumoraux, Centre de Recherche en Cancérologie, CRLC Val \\ d'Aurelle-Paul Lamarque, 1EMI229 Institut National de la Santé et de la Recherche Médicale, Montpellier, France
}

Epithelial mesenchymal transition (EMT) is a basic cellular process by which epithelial cells change their phenotype and become invasive cells within a three-dimensional setting. The embryo uses EMT to form threedimensional tissues from sheets of cells while the majority of EMT in the adult produces pathologies. Examples of EMT in the embryo include gastrulation, neural crest cell formation, heart valve and fibroblast formation and breakdown of the mullerian duct in the reproductive system. In pathology, kidney/liver fibrosis and cancer progression/metastasis have been shown to invoke EMT mechanisms.

Though the process of EMT was first discussed in the late 1970s and early 1980s in the context of developmental biology, it was not widely appreciated until the middle 1990 s and the field became much more topical as it was discovered by cancer biologists. The first papers on experimental analysis of EMT [Greenburg and Hay, 1982; Newgreen and Gibbins, 1982; Runyan and Markwald, 1983] all had a developmental focus looking at lens, neural crest and heart development, respectively. Some earlier work did not adopt the same title but was EMT nonetheless, for example in the neural crest field what we now refer to as EMT was mostly called 'migration onset' or 'delamination' in the 1970s and 1980s [Newgreen and Gibbins, 1982]. The EMT concept was extended quite early to reproductive biology, specifically to trophoblast invasiveness and endometrial receptivity at embryo implantation [Denker, 1986; Denker, 1990]. By 1992, there were still fewer than 75 papers in this area, but, notably, effects of extracellular matrix and growth factors on EMT in cancer cell lines were examined [Tucker et al., 1990; Valles et al., 1990]. Studies on EMT in cancer continued to accumulate throughout the 1990s and showed a surge with the finding of common transcriptional regulators of EMT in development and cancer [Cano et al., 2000].

More recently, there has been a surge in interest in this area as pathologists have related wound healing and fibrosis of the heart, liver and kidney to EMT, and the EMT phenotype has been linked to cancer stem cells. If the current rate is maintained, there will be approximately 855 articles in 2010 on EMT listed on ISI Web of Science using a search for 'epithelial* AND mesenchymal*' AND 'transition OR transformation', where the total is currently 629 (out of 3,477 primary papers returned by the search for all years). Among all EMT papers identified, $27 \%$ have been published since the start of 2009 , consistent with the

\section{KARGER}

Fax +4161306 1234

E-Mail karger@karger.ch

www.karger.com
(C) 2010 S. Karger AG, Basel

$1422-6405 / 11 / 1932-0004 \$ 38.00 / 0$

Accessible online at:

www.karger.com/cto
Prof. Erik Thompson

St. Vincent's Institute and University of Melbourne, Department of Surgery

Room 210, Clinical Sciences Building, St. Vincent's Hospital

29 Regent Street, Fitzroy, Melbourne, VIC 3065 (Australia)

Tel. +61 39288 2569, Fax +61 39416 2676, E-Mail rik@svi.edu.au 
exponential increase in this field in recent years. Only $9.5 \%$ of those are attributable to development - the oldest area of EMT research. In contrast, the areas of cancer and organ fibrosis are the hottest areas, each with approximately one third of the total output published in this recent period. The category of cell biology, which includes biochemistry and molecular biology and focuses on mechanisms of EMT rather than the cell source, has also increased in this later period, accounting for some $25 \%$ of publications. Categories are as identified in the Web of Science database. These data confirm a translational shift towards the more disease-related EMT and the underlying mechanisms that will underpin therapeutic advances, and reflect the number of researchers in these fields relative to the 'traditional' EMT area of developmental biology.

The 1st International EMT Meeting was organized in Port Douglas, Qld., Australia, in 2003. This 'Boden Conference on Epithelial-Mesenchymal Transitions' was held on October 5-8, 2003, at Port Douglas. The meeting was convened locally by Don Newgreen, Erik Thompson and Guy Lyons, and had an international committee chaired by Prof. Elizabeth Hay (USA) including Mina Bissell (USA), Suresh Mohla (USA), Shoukat Dedhar (Canada), Masatoshi Takeishi (Japan), Hans-Werner Denker (Germany) and Jean-Paul Thiery (France). This meeting grew out of the landmark collection of EMT reviews assembled as special editions to Acta Anatomica (Basel), now Cells Tissues Organs, in 1995 and 1996, and was expressly designed to bring together development, cancer and fibrosis communities in a way that had never been done before, and yet was so clearly needed. The principal supporters of the conference were the Boden Foundation, Australia, and the National Institutes of Health (NIH), USA. Cells Tissues Organs devoted another special issue to papers originating from that conference (volume 179, issues 1-2). The Second International EMT meeting was organized in Vancouver, B.C., Canada, in 2005, by Shoukat Dedhar and Raghu Kalluri, and the international program committee comprising Elizabeth Hay (USA), Mina Bissell (USA), Kohei Miyazono (Japan), Suresh Mohla (USA), Don Newgreen (Australia), Pierre Savagner (France), Jean-Paul Thiery (France), Erik Thompson (Australia) and Robert Weinberg (USA). The meeting was made possible with generous support from the Canadian Institutes for Health Research and the National Cancer Institute of Canada and an NIH conference grant. Papers arising from that meeting are found in volume 185 (2007) of Cells Tissues Organs.

Out of the Desert: The 4th TEMTIA Meeting
The 3rd TEMTIA Meeting was organized in Krakow, Poland, in 2007. It was convened by Pierre Savagner, Aristidis Moustakas, Antonio Garcia de Herreros and Amparo Cano as an EMBO Workshop, co-sponsored by TEMTIA and the Marie-Curie Epiplastcarcinoma EURTN network, and was supported by OSI Pharmaceuticals, the Ludwig Institute for Cancer Research (Uppsala, Sweden), Merck Serono, Landes Biosciences and S. Karger AG. The International Program Committee included Shoukat Dedhar (Canada), Raghu Kalluri (USA), Suresh Mohla (USA), Don Newgreen (Australia), Angela Nieto (Spain), Ray Runyan (USA) and Kristin Verschueren (Belgium). This meeting introduced the Elizabeth $\mathrm{D}$. Hay Lecture to honor a pioneering scientist in the field of EMT, who sadly passed away in 2007 [Trelstad, 2004; Watt, 2004; Svoboda and Gordon, 2008] (see also http://www.nlm.nih.gov/changingthefaceofmedicine/ physicians/biography_141.html). The Inaugural Betty D. Hay Lecture was presented by preeminent EMT researcher Jean-Paul Thiery, A*STAR, Singapore (EMT in Neural Crest and Cancer), at the Krakow meeting. As an EMBO workshop, a meeting report was published in EMBO Reports [Acloque et al., 2008], and Developmental Dynamics published a special issue on EMT in honor of Dr. Hay including [Svoboda and Gordon, 2008].

This 5th Special Edition of Cells Tissues Organs on Epithelial-Mesenchymal Transitions arises from the 4th International Conference on EMT, which was convened by Ray Runyan and Parker Antin on the 23rd-26th of September in 2009 in Tucson, Ariz., USA. An international program committee comprising S. Dedhar (Canada), D. Newgreen (Australia), P. Savagner (France), E. Thompson (Australia) and A. Moustakas (Sweden) created a dynamic program straddling the themes of physiological EMT (embryological development and placentation); pathological EMT (carcinoma progression, metastasis, fibrosis and wound healing); functional aspects of EMT (modulation of cell-cell adhesion, induction of cell motility and control of cell differentiation); commonality of EMT pathways; modulation of EMT; posttranscriptional regulation of EMT, and directions and issues in EMT research. Selected articles from these areas were solicited from speakers at the meeting for this special issue. As suggested in our title, the Tucson conference and this special issue celebrated the further emergence of EMT research into the mainstream of biomedical research, with landmark discoveries into important roles of EMT in the pathology of fibrosis and the manifestations of therapeutic resistance and metastatic competence in malignancy.

Cells Tissues Organs 2011;193:4-7 
The articles of this special issue of Cells Tissues Organs are arranged in a continuum starting with articles focused on signaling pathways and regulatory mechanisms, with important new advances in TGF- $\beta_{1}$ signaling in carcinoma-associated EMT, such as the unexpected role of c-Abl in repressing TGF- $\beta_{1}$-induced EMT in carcinoma [Allington and Schiemann, 2011]; the interplay between the non-Smad PI3 kinase-Akt-mTOR axis and EMT-associated invasion in response to TGF- $\beta$ [Lamouille and Derynck, 2011], and the complex stage-dependent opposing roles for Smad3 in the generation of myofibroblasts in organ fibrosis [Masszi and Kapus, 2011]. This is followed by a comprehensive review of the growth factor pathways regulating either EMT or MET with known relevance to metastasis, again with emphasis on their interdependence and interaction [Said and Williams, 2011]. Developmental scenarios/regulators are represented by work on dystrogylcan in chick gastrulation [Nakaya et al., 2011] and periostin in palate fusion [Kitase et al., 2011]; fibrotic kidney disease with angiotensin II downstream of the intrarenal renin-angiotensin system, which operates both through and independent of TGF- $\beta_{1}$ [Burns and Thomas, 2011], and carcinoma progression with articles on the E-cadherin repressor interactome in breast cancer systems [Hugo et al., 2011] and cooperation in EMT-regulating signals between oncostatin $M$, hepatocyte growth factor and TGF- $\beta$ in carcinoma EMT, arising from a survey of some 60 growth factors/cytokines in 30 cell lines [Argast et al., 2011]. These articles capture the current flavor of complexity surrounding EMT regulation, with a large number of regulatory pathways across the different models. Emphasis on regulatory hierarchies and cross modulation are a constant theme, as are the cellular manifestations that underpin the role of EMT in disease.

The success of this 4 th meeting hosted by TEMTIA the EMT International Association (http://www.mtci. com.au/temtia.html or <http://www.emtmeeting.org >), is testament to the continued recognition of EMT as an important process in many disciplines. Indeed, the growing acceptance and interest in EMT has seen a proliferation of EMT meetings, including an American Association for Cancer Research Special Conference on EMT (Arlington, Va., USA, March 2010) and a Keystone Symposium on Epithelial Plasticity and Epithelial to Mesenchymal Transition (January 21-26, 2011, Vancouver, B.C., Canada). The 5th International Epithelial Mesenchymal Transition Meeting (TEMTIA V) is set for Biopolis, Singapore, October 10-13, 2011, and will be co-convened by Jean-Paul Thiery and Erik Thompson, with an International Committee comprising Shoukat Dedhar (Canada), David Epstein (USA), Raghu Kalluri (USA), Don Newgreen (Australia), Angela Nieto (Spain), Raymond Runyan (Spain), Pierre Savagner (France), Guojun Sheng (Japan), Bob Weinberg (USA), Alice Wong (Hong Kong), and Hongquan Zhang (China). The TEMTIA IV conference in Tucson would not have been possible without the generous support of an NIH (USA) R13 Conference grant representing numerous Institutes [NIHLB (primary sponsor), NCI, NICHD, NIDCR; NIH 1R13HL97541-1], OSI Pharmaceuticals, R\&D Systems, the American Association of Anatomists and Procter \& Gamble Global Biotechnology.

\section{References}

-Acloque, H., J.P. Thiery, M.A. Nieto (2008) The physiology and pathology of the EMT. Meeting on the epithelial-mesenchymal transition. EMBO Rep 9: 322-326.

Allington, T.M., W.P. Schiemann (2011) The cain and Abl of epithelial-mesenchymal transition and transforming growth factor- $\beta$ in mammary epithelial cells. Cells Tissues Organs 193: 98-113.

Argast, G.M., P.M. Iain, J.M. O’Connor, D.M. Shaaban, D.M. Epstein, J.A. Pachter, J.L. Kan (2011) Cooperative signaling between oncostatin $M$, hepatocyte growth factor and transforming growth factor- $\beta$ enhances epithelial to mesenchymal transition in lung and pancreatic tumor models. Cells Tissues Organs 193: 114-132.
Burns, W.C., M.C. Thomas (2011) Angiotensin II and its role in tubular epithelial to mesenchymal transition associated with chronic kidney disease. Cells Tissues Organs 193: 74-84.

Cano, A., M.A. Perez-Moreno, I. Rodrigo, A. Locascio, M.J. Blanco, M.G. del Barrio, F. Portillo, M.A. Nieto (2000) The transcription factor snail controls epithelial-mesenchymal transitions by repressing E-cadherin expression. Nat Cell Biol 2: 76-83.

Denker, H.-W. (1986) Epithel-Epithel-Interaktionen bei der Embryo-Implantation: Ansätze zur Lösung eines zellbiologischen Paradoxons. Anat Anz 160(Suppl): 93-114.
Denker, H.-W. (1990) Trophoblast-endometrial interactions at embryo implantation: A cell biological paradox, in Denker, H.-W., J.D. Aplin (eds): Trophoblast Invasion and Endometrial Receptivity. Novel Aspects of the Cell Biology of Embryo Implantation. Trophoblast Res, New York, Plenum Medical Book Company, vol 4, pp 3-29.

Greenburg, G., E.D. Hay (1982) Epithelia suspended in collagen gels can lose polarity and express characteristics of migrating mesenchymal cells. J Cell Biol 95: 333-339.

Hugo, H.J., M.I. Kokkinos, T. Blick, M.L. Ackland, E.W. Thompson, D.F. Newgreen (2011) Defining the E-cadherin repressor interactome in epithelial-mesenchymal transition: The PMC42 model as a case study. Cells Tissues Organs 193: 23-40. 
Kitase, Y., K. Yamashiro, K. Fu, J.M. Richman, C.F. Shuler (2011) Spatiotemporal localization of periostin and its potential role in epithelial-mesenchymal transition during palatal fusion. Cells Tissues Organs 193: $53-$ 63.

Lamouille, S., R. Derynck (2011) Emergence of the phosphoinositide 3-kinase-akt-mammalian target of rapamycin axis in transforming growth factor- $\beta$-induced epithelialmesenchymal transition. Cells Tissues Organs 193: 8-22.

Masszi, A., A. Kapus (2011) Smaddening complexity: The role of Smad3 in epithelial-myofibroblast Transition. Cells Tissues Organs 193: 41-52.

Nakaya, Y., E.W. Sukowati, C. Alev, F. Nakazawa, G. Sheng (2011) Involvement of dystroglycan in epithelial-mesenchymal transition during chick gastrulation. Cells Tissues Organs 193: 64-73.
Newgreen, D.F., I.L. Gibbins (1982) Factors controlling the time of onset of the migration of neural crest cells in the fowl embryo. Cell Tissue Res 224: 145-160.

Runyan, R.B., R.R. Markwald (1983) Invasion of mesenchyme into three-dimensional collagen gels: a regional and temporal analysis of interaction in embryonic heart tissue. Dev Biol 95: 108-114.

Said, N.A., E.D. Williams (2011) Growth factors in induction of epithelial-mesenchymal transition and metastasis. Cells Tissues Organs 193: 85-97.
Svoboda, K.H., M. Gordon (2008) A tribute to Elizabeth D. Hay, 1927-2007. Dev Dyn 237: 2605-2606.

Trelstad, R.L. (2004) The extracellular matrix in development and regeneration. An interview with Elizabeth D. Hay. Int J Dev Biol 48: 687694

Tucker, G.C., B. Boyer, J. Gavrilovic, H. Emonard, J.P. Thiery (1990) Collagen-mediated dispersion of NBT-II rat bladder carcinoma cells. Cancer Res 50: 129-137.

Valles, A.M., B. Boyer, J. Badet, G.C. Tucker, D. Barritault, J.P. Thiery (1990) Acidic fibroblast growth factor is a modulator of epithelial plasticity in a rat bladder carcinoma cell line. Proc Natl Acad Sci USA 87: 1124-1128.

Watt, F. (2004) Women in cell science - Elizabeth Hay. J Cell Sci 117: 4617-4618.

\section{Editorial Note}

With this volume, Cells Tissues Organs continues a series of Special Topic Issues on EMT. This journal has pioneered publishing on EMT under its previous name Acta Anatomica, i.e. at a time when EMT/MET was still considered a quite new and debated concept. The editors are happy to see the high degree of recognition that this concept has received in the meantime and that it has much stimulated research, in particular in the areas of developmental and tumor biology. Cells Tissues Organs plans to maintain one of its focuses on this exciting and rapidly expanding field of research.

H.-W. Denker, Essen

Previous Special Topic Issues on EMT:

- Acta Anatomica Vol. 154, No. 1, 1995: Epithelial-Mesenchymal Transitions. Part I. Guest Editor: D.F. Newgreen, Melbourne

- Acta Anatomica Vol. 156, No. 3, 1996: Epithelial-Mesenchymal Transitions. Part II. Guest Editor: D.F. Newgreen, Melbourne

- Cells Tissues Organs Vol. 179, No. 1-2, 2005: Recent Progress in Epithelial-Mesenchymal Transitions. Development - Cancer - Pathology.

Guest Editors: D.F. Newgreen and E.W. Thompson, Melbourne

- Cells Tissues Organs Vol. 185, No. 1-3, 2007: Advances in Epithelial-Mesenchymal Transitions.

Guest Editors: E.W. Thompson and D.F. Newgreen, Melbourne 